\title{
Modest effect of p53, EGFR and HER-2/neu on prognosis in epithelial ovarian cancer: a meta-analysis
}

\author{
P de Graeff ${ }^{1,4}$, APG Crijns ${ }^{1,4}$, S de Jong ${ }^{2}$, M Boezen $^{3}$, WJ Post ${ }^{3}$, EGE de Vries ${ }^{2}$, AGJ van der Zee' \\ and GH de Bock ${ }^{*, 3}$
}

'Department of Gynaecologic Oncology, University Medical Centre Groningen, University of Groningen, Hanzeplein I, Groningen 97। 3 GZ, The Netherlands; '2Department of Medical Oncology, University Medical Centre Groningen, University of Groningen, Hanzeplein I, Groningen 97 I 3 GZ, The Netherlands; ${ }^{3}$ Department of Epidemiology, University Medical Centre Groningen, University of Groningen, Hanzeplein I, Groningen 97 I 3 GZ, The Netherlands

\begin{abstract}
BACKGROUND: P53, EGFR and HER-2/neu are the most frequently studied molecular biological parameters in epithelial ovarian cancer, but their prognostic impact is still unequivocal. We performed a meta-analysis to more precisely estimate their prognostic significance. METHODS: Published studies that investigated the association between p53, EGFR and HER-2/neu status and survival were identified. Meta-analysis was performed using a DerSimonian-Laird model. Publication bias was investigated using funnel plots and sources of heterogeneity were identified using meta-regression analysis.

RESULTS: A total of 62 studies were included for p53, 15 for EGFR and 20 for HER-2/neu. P53, EGFR and HER-2/neu status had a modest effect on overall survival (pooled HR I.47, 95\% Cl I.33-1.6I for p53; HR 1.65, 95\% Cl I.25-2.19 for EGFR and HR I.67, 95\% Cl I.34-2.08 for HER-2/neu). Meta-regression analysis for p53 showed that FIGO stage distribution influenced study outcome. For EGFR and HER-2/neu, considerable publication bias was present.

CONCLUSIONS: Although p53, EGFR and HER-2/neu status modestly influences survival, these markers are, by themselves, unlikely to be useful as prognostic markers in clinical practice. Our study highlights the need for well-defined, prospective clinical trials and more complete reporting of results of prognostic factor studies.

British Journal of Cancer (2009) I 01, |49-159. doi:10.1038/sj.bjc.6605 II2 www.bjcancer.com

Published online 9 June 2009
\end{abstract}

(c) 2009 Cancer Research UK

Keywords: p53; EGFR; HER-2/neu; ovarian cancer; meta-analysis

Epithelial ovarian cancer is the leading cause of death from gynaecological cancers in the Western world. This high mortality is related to the difficulty to detect ovarian cancer at an early stage as well as the lack of effective therapies for advanced-stage disease (Cannistra, 2004).

Prognostic factors are defined as phenotypes, which correlate with the duration of (progression-free) survival (Agarwal and Kaye, 2005). In ovarian cancer, well-known clinicopathological prognostic factors in early-stage disease include differentiation grade and tumour rupture during surgery, whereas in late-stage disease histiotype, patient age, performance status and residual tumour after primary surgery are important prognostic factors (Vergote et al, 2001; Winter et al, 2007). Although these parameters do reflect biological features of both tumour and patient, they do not allow adequate prediction of outcome for the individual patient. The discovery of molecular biological prognostic factors should aid in a more accurate prediction of clinical outcome and may also reveal novel predictive factors and therapeutic targets (Oldenhuis et al, 2008).

\footnotetext{
*Correspondence: Dr GH de Bock; E-mail: g.h.de.bock@epi.umcg.nl

${ }^{4}$ These authors contributed equally to the work

Received 27 January 2009; revised 22 April 2009; accepted I May 2009; published online 9 June 2009
}

The most frequently studied putative molecular biological prognostic factors in ovarian cancer are the tumour suppressor protein 53 (p53), and the oncogenes epidermal growth factor receptor (EGFR) and human epidermal growth factor receptor 2 (HER-2/neu). These markers also hold considerable promise as therapeutic targets. Agents targeting p53, EGFR and HER-2/neu proteins are currently under investigation in clinical trials (Dinh et al, 2008). However, evidence regarding their prognostic value with respect to survival is still inconclusive. Results of systematic reviews, including one from our institution, showed that these markers might predict prognosis in ovarian cancer, and also suggested considerable methodological variability (Crijns et al, 2003; Hall et al, 2004). The identification of these methodological weaknesses and sources of heterogeneity is important to improve the quality of future prognostic and predictive factor studies in ovarian cancer and other tumour types.

The aim of this study was to more precisely estimate the prognostic value of these markers and to adjust for methodological variability. We have used statistical methods developed by Parmar et al (1998) to indirectly estimate hazard ratios from Cox regression analyses and $P$ values from log-rank tests, enabling us to incorporate a large number of studies in our meta-analyses. Moreover, we performed an in-depth analysis of study quality, the presence of publication bias and the extent and sources of heterogeneity between published studies. 
minimum and maximum), assay method and scoring protocol used, number of marker positive and negative tumours, numbers of (disease specific and overall) death, and results of univariate survival analyses.

\section{Assessment of study quality and publication bias}

Study quality was assessed independently by two investigators (PdG and APGC) by means of a predefined form. As there are no generally accepted standards for measuring study quality, this form was derived from the work of McShane et al (2005) and Hayes et al (1996) (Supplementary Table 2). In summary, the following criteria were investigated: whether (1) the study reported inclusion and exclusion criteria; (2) study data were prospectively or retrospectively gathered; (3) patient and tumour characteristics were sufficiently described; (4) the assay used to measure biomarker expression was sufficiently described; (5) a definition of the study endpoint was provided; (6) the follow-up time of patients in the study was described; (7) the study reported how many patients were lost to follow-up or were not available for statistical analysis. Studies with a total score of 8 were considered to show the highest study quality, whereas a zero score indicated the lowest quality.

Additionally, studies were scored as phase I-III prognostic marker studies according to the classification proposed by Simon and Altman (1994). Early exploratory studies are designated phase I studies, whereas phase II studies investigate the association of a biomarker with patient prognosis and are hypothesis generating in nature, and phase III studies are large confirmatory studies of prestated hypotheses.

Publication and selection bias were investigated through a funnel plot (Egger et al, 1997).

\section{Statistical analysis}

Statistical analyses were carried out using SPSS version 12.01 (SPSS, Chicago, IL, USA), Review Manager version 4.2 (The Cochrane Collaboration, the Nordic Cochrane Centre, Copenhagen, Denmark) and MLWIN version 2.0 (Centre for Multilevel Modelling, University of Bristol, Bristol, UK).

The first goal of our meta-analysis was to obtain a log-hazard ratio and its standard error for each study according to methods previously described by Parmar et al (1998). If the study reported results of a univariate Cox regression analysis, log-hazard and its standard error were directly included in the meta-analysis. When the study did not report the standard error, it was estimated from the $95 \%$ confidence interval $(\mathrm{CI})$ or $P$ value of univariate Cox regression analyses. If results of univariate Cox regression analyses were not presented in the paper, the log-hazard ratio and its standard error were estimated indirectly from $P$ values of the logrank test. Subsequently we performed a meta-analysis using the DerSimonian-Laird random effects model (DerSimonian and Laird, 1986), applying the inverse of variance as a weighing factor. Heterogeneity was investigated by use of the $I^{2}$ statistic, which takes values from 0 to $100 \%$ (Higgins and Thompson, 2002). An $I^{2}$ value $>50 \%$ was considered to represent substantial heterogeneity between studies.

Quantitative assessment of sources of heterogeneity was undertaken by meta-regression analysis (Thompson and Higgins, 2002). The following potential sources of heterogeneity were explored: study quality score, year of publication $(<$ or $>$ median year of publication), data collection (prospective or retrospective), region (Europe, United States, Asia or other), FIGO stage $(<$ or $>50 \%$ FIGO stage III/IV tumours), tumour type $(<50 \%$ or $>50 \%$ serous tumours), differentiation grade $(<50 \%$ or $>50 \%$ grade III or undifferentiated tumours), type of tumour tissue (frozen or paraffin-embedded), assay method (IHC or other), primary antibody (monoclonal or polyclonal), cut-off value for positive 
marker expression $(<$ or $>$ median percentage of positive tumours) and percentage of positive tumours $(<$ or $>$ number of percentage positive tumours). For each potential source of heterogeneity, a multilevel model was developed with the logHR as dependent variable and the sources of heterogeneity as independent variables.

\section{RESULTS}

\section{Study characteristics}

For p53, 62 studies reporting results of 75 analyses in 9448 patients were included (Supplementary Table 3; median study size 102 patients, range 20-783; Hartmann et al, 1994; Klemi et al, 1995; Allan et al, 1996; Eltabbakh et al, 1997; Viale et al, 1997; Darai et al, 1998; Marx et al, 1998; Silvestrini et al, 1998; Anttila et al, 1999; Baekelandt et al, 1999; Kassim et al, 1999; Wen et al, 1999; Blegen et al, 2000; Laframboise et al, 2000; Levesque et al, 2000; Ozalp et al, 2000; Schildkraut et al, 2000; Shahin et al, 2000; Birner et al, 2001; Howells et al, 2001; Reles et al, 2001; Saegusa et al, 2001; Schuyer et al, 2001; Skirnisdottir et al, 2001a; Berker et al, 2002; Hawes et al, 2002; Pieretti et al, 2002; Sagarra et al, 2002; Havrilesky et al, 2003; Ikeda et al, 2003; Konstantinidou et al, 2003; Nakayama et al, 2003; Tachibana et al, 2003; Wisman et al, 2003; Bali et al, 2004; Ceccaroni et al, 2004; Iba et al, 2004; Nielsen et al, 2004; Seo et al, 2004; Concin et al, 2005; Goodheart et al, 2005; Kaern et al, 2005; Kaiser et al, 2005; Terauchi et al, 2005; Green et al, 2006; Lee et al, 2006; Ueno et al, 2006; Yakirevich et al, 2006; de Graeff et al, 2006; Brustmann, 2007; Galic et al, 2007; Malamou-Mitsi et al, 2007; Materna et al, 2007; Psyrri et al, 2007; Bartel et al, 2008; Darcy et al, 2008; Garcia-Velasco et al, 2008; Giordano et al, 2008; Kobel et al, 2008; Leffers et al, 2008; Tomsova et al, 2008; Vartiainen et al, 2008). There were 13 prospective studies and 49 retrospective studies. All studies were designated phase II biomarker studies. No phase III biomarker studies were found, although two large studies fulfilled almost all requirements (de Graeff et al, 2006; Darcy et al, 2008). Most studies used IHC $(n=60)$ or mutational analysis (single-strand conformation polymorphism analysis and/or sequencing, $n=11$ ) to determine p53 status. Other methods included fluorescence in situ hybridisation (FISH, $n=1)$ and immunoassays $(n=2)$. For IHC staining, the most frequently used antibodies were DO1 $(n=10)$ and DO7 $(n=32)$. Six studies did not specify the antibody used. Cut-off values for positive immunostaining varied widely, ranging from $>5 \%$ to $>90 \%$ nuclear staining. The median percentage of $\mathrm{p} 53$ positive tumours was $50 \%$ (range $13.7-82.0 \%$ ). A significant association of p53 expression with overall survival in univariate analysis was reported in 29 (38.6\%) analyses, of which 25 reported an association with poor survival and 4 an association with improved survival.

For EGFR, 15 studies in 2471 patients were included in the metaanalysis (Supplementary Table 4; median study size 106 patients, range 40-783; Kaufmann et al, 1995; Scambia et al, 1995; Bartlett et al, 1996; Fischer-Colbrie et al, 1997; Skirnisdottir et al, 2001b; Elie et al, 2004; Nielsen et al, 2004; Psyrri et al, 2005; Raspollini et al, 2005; Schilder et al, 2005; Wang et al, 2005; Castellvi et al, 2006; Lassus et al, 2006; Brustmann, 2008; de Graeff et al, 2008). Again, all studies were classified as phase II biomarker studies. Three studies prospectively collected data. Eleven studies performed IHC staining for determination of EGFR expression using five different antibodies and six cut-off values for positive EGFR expression. Other methods included ${ }^{125}$ EGF binding assay $(n=3)$ and RT-PCR $(n=1)$. Positive immunostaining was observed in $6.2-72.6 \%$ (median $35 \%$ ) of tumours, and in 7 studies $(63.6 \%$ ) EGFR expression predicted poor overall survival.

For HER-2/neu, 20 studies reporting results of 21 analyses in 3055 patients were subjected to final analysis (Supplementary Table 4; median study size 111 patients, range 40-783; Berchuck et al, 1990; Fajac et al, 1995; Kaufmann et al, 1995; Medl et al, 1995;
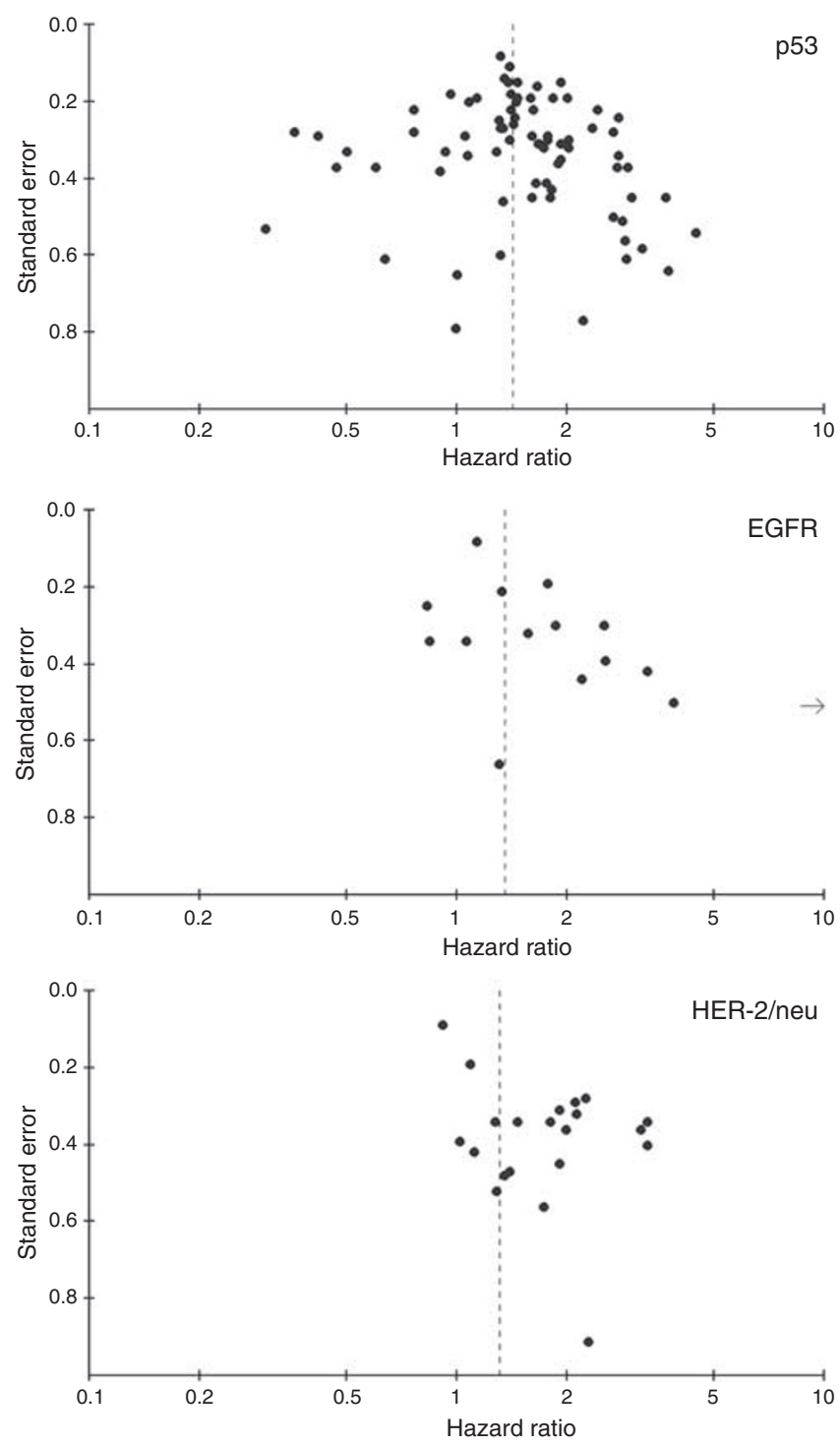

Figure 2 Funnel plots. Funnel plots showing the relationship between the effect size of individual studies (hazard ratios for overall survival, horizontal axis) and the precision of the study estimate (standard error, vertical axis) for p53, EGFR and HER-2/neu.

Wang et al, 1999, 2005; Davidson et al, 2000; Skirnisdottir et al, 2001b; Camilleri-Broet et al, 2004; Nielsen et al, 2004; Verri et al, 2005; Castellvi et al, 2006; Surowiak et al, 2006; Malamou-Mitsi et al, 2007; Pils et al, 2007; Steffensen et al, 2007; Tuefferd et al, 2007; de Graeff et al, 2008; Garcia-Velasco et al, 2008; Tomsova et al, 2008). All studies were designated phase II biomarker studies. Two studies prospectively collected patient data. Methods to determine HER-2/neu status included IHC $(n=16)$ with 3 studies additionally performing FISH for ambiguous cases, PCR $(n=1)$, FISH only $(n=1)$, Southern blot $(n=1)$ and HER-2/neu immunoassay $(n=1)$. Antibodies used for IHC staining included CB11 $(n=3)$, TA1 $(n=1), \operatorname{MCO} 102(n=1), \operatorname{NCL}-\mathrm{CBE}-356(n=1)$, the Herceptest kit $(n=4)$ and unspecified antibodies $(n=3)$. Five different cut-off values for positive HER-2/neu protein expression were used. The median percentage of positive tumours was $18.0 \%$ (range 5-57\%). Eight studies (40\%) reported that HER-2/neu was a significant predictor of overall survival in univariate analysis, of which one study reported an association between HER-2/neu staining and improved survival. 


\section{Quality assessment and publication bias}

The median quality score was 5 (range $1-8$ ) for p53, 5 for EGFR (range 3-7) and 5 for HER-2/neu (range 3-8; Supplementary Tables 3-5). High study quality was related to a high journal impact factor for p53 $(P=0.010)$, but not for EGFR $(P=0.59)$ and HER-2/neu $(P=0.65)$.

Investigation of bias by a funnel plot showed substantial funnel plot asymmetry for HER-2/neu and EGFR, suggesting the presence of publication and/or selection bias (Figure 2). For p53, no funnel plot asymmetry was found.

\section{Meta-analysis and assessment of heterogeneity}

P53 Meta-analysis of 53 studies on the prognostic value of p53 expression showed that aberrant of p53 status is associated with poor overall survival (HR obtained from DerSimonian-Laird random effects model: 1.55 (95\% CI 1.40-1.71); Figure 3), although there was heterogeneity between studies $\left(I^{2}=44.4 \%\right)$. Subgroup analysis revealed a prognostic impact for IHC studies, IHC studies with the DO7 antibody, studies using mutational analysis and studies with a quality score $>6$. However, considerable heterogeneity remained present, indicating that not all sources of heterogeneity could be accounted for (Table 1). When the meta-analysis was restricted to studies reporting results of (subgroup) analyses for serous tumours (Bali et al, 2004; Terauchi et al, 2005; Ueno et al, 2006; Yakirevich et al, 2006; Kobel et al, 2008; Vartiainen et al, 2008) p53 status was also a predictor of poor survival. Unfortunately, the number of studies reporting results for the other histological subtypes was too small to perform a pooled analysis. Meta-regression analysis revealed that the outcome of analysis was influenced by FIGO stage distribution. When results of six studies reporting results for stage III/IV tumours were subsequently pooled, p53 status was no longer of prognostic value (Table 1).

EGFR Results of meta-analysis for EGFR showed a significant relationship between overexpression of EGFR and poor patient outcome (HR: 1.65 (95\% CI 1.25-2.19); Figure 4). Although significant heterogeneity was present $\left(I^{2}=74.3 \%\right)$, the sources of heterogeneity could not be determined in meta-regression analysis. Restricting the analysis to studies that used IHC staining for determination of marker expression did not alter results of heterogeneity tests (Table 1). However, further analysis showed that heterogeneity was partly due to results of the study by Psyrri et al (2005). When this study was excluded from the meta-analysis, less heterogeneity was observed.

HER-2/neu Meta-analysis of univariate analyses on the prognostic value of HER-2/neu showed that overexpression of HER-2/neu is associated with poor overall survival (HR: 1.67 (95\% CI 1.34-2.08); Figure 5), but again considerable heterogeneity was present $\left(I^{2}=59.6 \%\right)$. Of note, none of the studies using immunohistochemical staining followed by FISH for ambiguous samples reported a statistically significant relationship between HER-2/neu expression and survival (Castellvi et al, 2006; Malamou-Mitsi et al, 2007; Tuefferd et al, 2007). The most important factor explaining the lack of homogeneity between studies was study quality, with studies of low quality reporting more significant results.

\section{DISCUSSION}

In this study, we present a pooled estimate of the prognostic value of p53, EGFR and HER-2/neu in epithelial ovarian cancer. Our results show that as single markers, p53, EGFR and HER-2/neu are not likely to be useful as prognostic factors in clinical practice (pooled HR for all included studies: 1.47 (95\% CI 1.33-1.61) for p53; 1.65 (95\% CI 1.25-2.19) for EGFR and 1.67 (95\% CI 1.34-2.08) for HER-2/neu). Furthermore, our study clearly indicates that adequate conduct and complete reporting are imperative for improving the quality of prognostic factor studies in ovarian cancer.

Although protein expression of p53 and EGFR as assessed by IHC staining has a modest effect on prognosis, neither p53 nor EGFR immunostaining predicts clinical outcome in a manner comparable to well-known clinicopathological prognostic factors such as tumour stage and residual tumour after primary surgery. Our results also show that $\mathrm{p} 53$ mutations have prognostic value in epithelial ovarian cancer, although this was of borderline significance. However, this analysis was affected by small sample size and methodological issues, such as the use of different techniques for mutational analyses and the analysis of different exons.

For HER-2/neu and EGFR, the ability to draw reliable conclusions from meta-analysis was affected by the presence of considerable publication bias for studies with a small sample size yielding non-significant results. The presented hazard ratios might, therefore, be an overestimation of the true effect size. More importantly, meta-regression analysis demonstrated that studies that are poorly designed or reported produce higher estimates of the prognostic value of HER-2/neu. This finding has previously been demonstrated in a meta-analysis of clinical trials, where incorporation of results of poor quality randomised controlled trials contributed to significant exaggeration of treatment efficacy (Moher et al, 1998).

It has long been appreciated that the histological subtypes of ovarian cancer show considerable differences with respect to stage at diagnosis, response to chemotherapy and underlying molecular abnormalities (Bell, 2005). This was recently demonstrated by Kobel et al (2008), who assessed the expression of 21 candidate biomarkers in a large cohort of 500 ovarian carcinomas and subsequently performed subgroup analyses for the different histological subtypes. Their results showed that the expression as well as the prognostic value of most biomarkers considerably varied between the subtypes. In this study, we assessed the prognostic value of p53 in six studies presenting (subgroup) analyses for $\mathrm{p} 53$ in serous tumours. The results of this analysis did not show a large difference between the prognostic value of p53 in serous tumours and it prognostic value in the entire cohort. Additionally, we performed a subgroup analysis for four studies reporting six analyses on the prognostic value of p53 in stage III/IV tumours. In this group, p53 was not of prognostic value. However, the number of studies that could be analysed was small and we were not able to perform a pooled analysis for the other histological subtypes. Our results underscore the importance of biomarker analysis in homogeneous subgroups of patients, such as patients with a particular disease stage, tumour type or differentiation grade. To perform these kinds of analyses, international collaboration is critical. Furthermore, the submission

Figure 3 Forest plot showing results of studies on the prognostic value of p53 expression. Hazard ratios and $95 \% \mathrm{Cl}$ (confidence interval) of individual studies for patients with p53 positive tumours. Hazard ratios: squares whose heights are inversely proportional to the standard error of the estimate, and their respective confidence intervals (horizontal lines). Summary hazard ratio: diamond with horizontal limits at the confidence limits and width inversely related to its standard error. Hazard ratios higher than I indicate an increased risk of death for patients with a tumour with aberrant p53 status. Abbreviations: $M U T=$ results of mutation analysis; $I H C=$ results of immunohistochemical staining; cyt= results for cytoplasmic immunostaining; nucl = results for nuclear immunostaining; $P$ arm = results for patients treated with cisplatin; $P C$ arm = results for patients treated with cisplatin/ cyclophosphamide. 
p53, EGFR and HER-2/neu in ovarian cancer

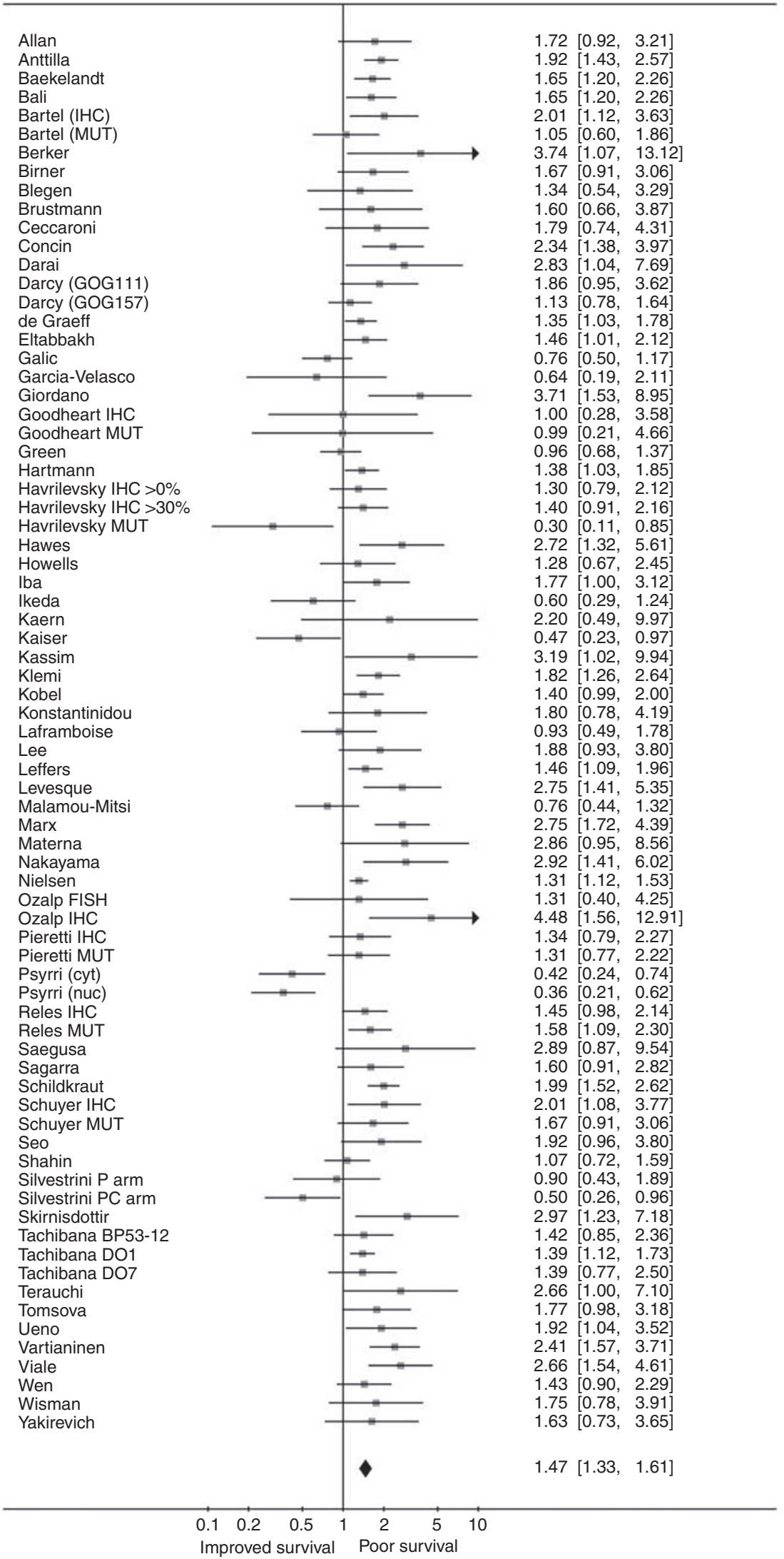


Table I Summarized hazard ratios

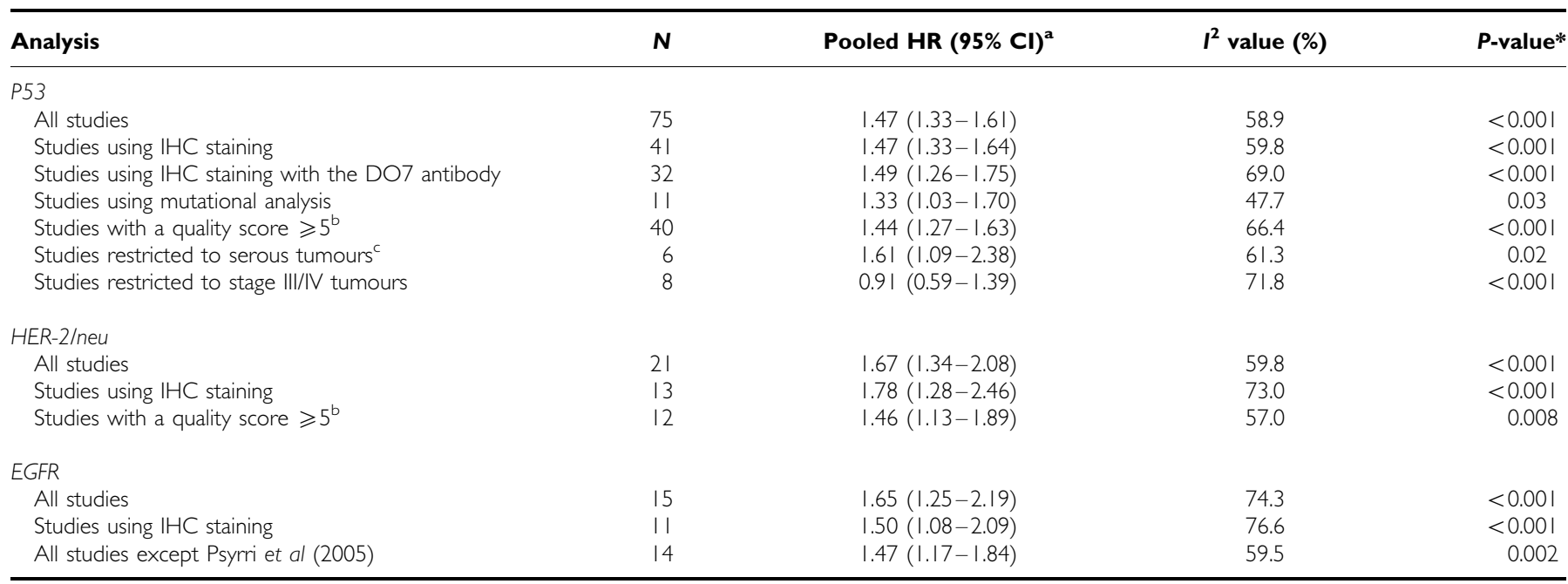

$\mathrm{HR}=$ hazard ratio; $95 \% \mathrm{Cl}=95 \%$ confidence interval; $\mathrm{HC}=$ immunohistochemical staining. ${ }^{\text {aPooled }}$ hazards ratios were obtained from using a DerSimonian-Laird random effects model, applying the inverse of variance as a weighing factor. ${ }^{b}$ Cut-off values for quality scores were based on the median quality score of included studies for a specific marker. ${ }^{C}$ Four studies restricted to serous tumours and two studies (Ueno et al, 2006; Kobel et al, 2008) reporting results of subgroup analysis for serous tumours. *P values obtained from $\chi^{2}$-test for heterogeneity.

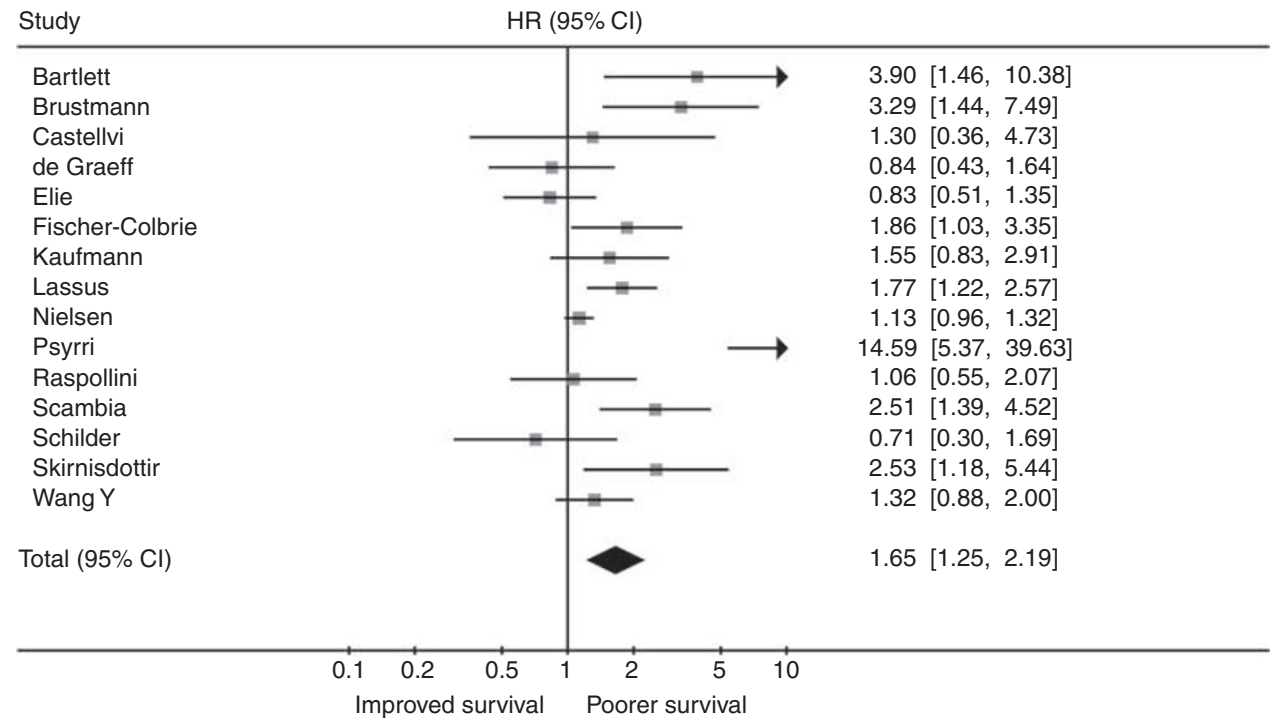

Figure 4 Forest plot showing results of studies on the prognostic value of EGFR expression. Hazard ratios and $95 \%$ confidence intervals for patients with EGFR positive tumours (symbols as in Figure 3).

of raw, uncategorised study data to public databases would allow for analysis of specific subgroups although maintaining prognostic power.

Most studies in the meta-analysis used IHC staining to study expressions of p53, EGFR and HER-2/neu. Although IHC staining is simple and cost-effective to perform, results are highly dependent on a variety of methodological factors such as storage time and fixation method of paraffin-embedded tissues, choice of primary antibody and IHC staining protocol (Jacquemier et al, 1994; Hall et al, 2004). In this study, differences in IHC staining protocols and cut-off values for positive protein expression ranging from $>5$ to $>90 \%$ positively stained cells may have contributed to the observed heterogeneity. Our results, therefore, make a strong case for international consensus on staining and scoring protocols.

As a first step towards quality assessment of prognostic factor studies to be included in meta-analyses, we have developed a quality score. For meta-analyses evaluating results of both clinical trials and diagnostic studies, such criteria are available and are widely used to either exclude studies low-quality studies or evaluate study quality (Jadad et al, 1996; Whiting et al, 2003). As our quality score was newly developed for this study and was not extensively validated, we chose not to exclude studies from statistical analysis beforehand because of a low score. Based on results of meta-regression analysis we do, however, believe that it provides a good estimation of study quality. In future studies, our quality score might serve as a further step towards the development of evidence-based quality assessment tools for metaanalyses of prognostic factor studies. In addition, the use of the recently published REMARK guidelines for reporting of prognostic factor studies will aid in a more complete and transparent reporting (McShane et al, 2005), thereby also increasing the number of high-quality studies that can be included in a meta-analysis. 


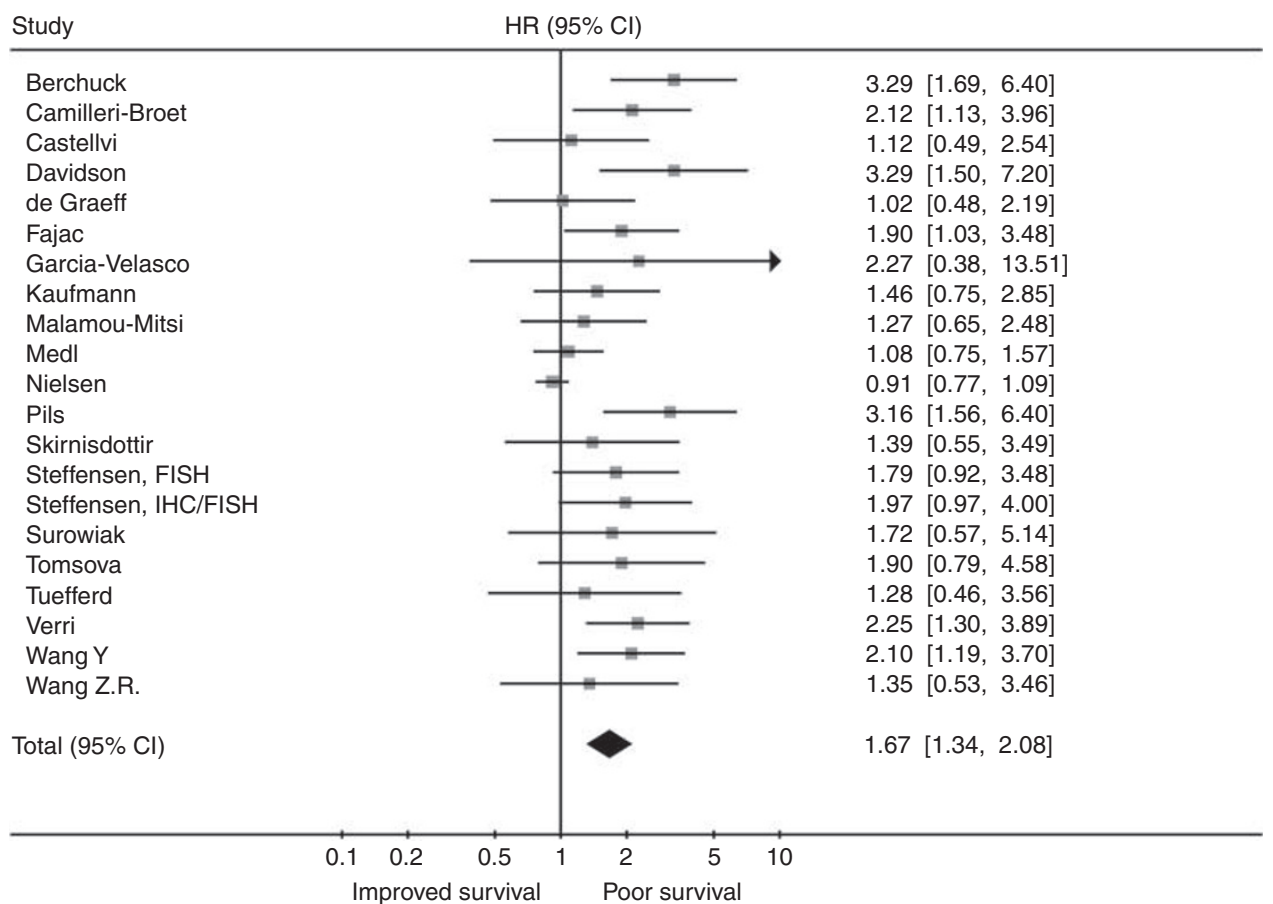

Figure 5 Forest plot showing results of studies on the prognostic value of HER-2/neu expression. Hazard ratios and $95 \% \mathrm{Cl}$ (confidence intervals) for patients with HER-2/neu positive tumours (symbols as in Figure 3).

We have also designated all studies phase I-III prognostic factor studies according to a classification proposed by Simon and Altman (1994). Although several large studies on the prognostic value of p53 and HER-2/neu have been performed, no studies met the stringent criteria for phase III biomarker studies. A prespecified hypothesis, the description of eligibility criteria and a sufficiently large number of patients were often lacking. In addition, almost none of the studies were specifically designed to determine the prognostic impact of p53, EGFR or HER-2/neu as single markers. These results underscore the need for welldesigned studies with clearly stated hypotheses that examine the relationship between biomarker expression and clinical outcome.

Although this study shows that p53, EGFR and HER-2/neu immunostaining do not have a strong direct relationship with survival, it is more than likely that their respective pathways do influence patient prognosis. In future studies, several approaches could be taken to elucidate the prognostic value of these pathways. For instance, IHC staining of activated (phosphorylated) receptors and key regulatory proteins involved in upstream and downstream signalling may be more informative than immunostaining of single markers regardless of their activation status (Wang et al, 2005; de Graeff et al, 2008). In addition, other methods to assess pathway activation status may be employed to identify prognostic factors. For instance, EGFR amplification as determined by FISH has been shown to be independently associated with poor survival in vulvar cancer and in head and neck squamous cell carcinomas (Chung et al, 2006; Growdon et al, 2008). Two recent reports in ovarian cancer also suggest that increased gene copy number of EGFR is more strongly related to survival than protein expression (Lassus et al, 2004, 2006).

Other attractive approaches for the identification of novel prognostic and predictive factors include the identification of genes and pathways by microarray analysis. Traditional prognostic factor studies, including those on p53, HER-2/neu and EGFR, have until now mainly focused on the prognostic value of single genes. Over the past years, it has become apparent that this 'one gene, one outcome' hypothesis is an oversimplification of the multiple genetic and epigenetic mechanisms that account for ovarian cancer survival. Using pathway analysis of large datasets such as microarray data (Bild et al, 2006), alterations in the p53, EGFR and HER-2/neu pathways rather than single genes can be analysed. Ultimately, the identification or deregulated pathways in a single tumour may lead to a more precise estimation of patient prognosis and might also reveal novel therapeutic targets. However, these studies often need a far more complex design and statistical analysis compared to single marker studies. It is, therefore, especially important to address methodological issues when designing and reporting these analyses, and to take possible sources of heterogeneity into account.

There are some limitations to this meta-analysis. Firstly, especially for EGFR and HER-2/neu considerable heterogeneity was observed. When subgroup analyses for more homogeneous groups of studies was performed, for example, only studies performing IHC staining, heterogeneity remained present. This indicates that not all sources of heterogeneity could be accounted for in this meta-analysis, and that results should be interpreted with caution. Secondly, we have restricted our analysis to published studies written in English or German. Thirteen, mostly small studies that met eligibility criteria according to the abstracts were excluded based on language criteria. This may result in publication or language bias leading to an overestimation of effect sizes (Egger et al, 1997; Pham et al, 2005). Although this was not the case for p53, there was clear evidence of publication bias for EGFR and HER-2/neu. Thirdly, our meta-analysis is based on unadjusted estimates, whereas a more precise estimate could be obtained using a multivariate analysis adjusting for clinicopathological variables. However, multivariate analyses reported in the included studies used various models and different covariates, and could, therefore, not be combined into a pooled estimate.

In conclusion, our study shows that although aberrations of p53 and EGFR have a modest effect on survival in ovarian cancer, they are currently unlikely to influence clinical decision-making. 
Identification of multiple methodological flaws and sources of heterogeneity in currently available prognostic factor studies should contribute to improve design and reporting of future prognostic and predictive factor studies. Hopefully, this way, deregulated molecular biological factors/pathways will be identified that will make a difference in clinical decision making, ultimately resulting in effective, individualised targeted therapy for ovarian cancer patients.

Supplementary Information accompanies the paper on British Journal of Cancer website (http://www.nature.com/bjc)

\section{REFERENCES}

Agarwal R, Kaye SB (2005) Prognostic factors in ovarian cancer: how close are we to a complete picture? Ann Oncol 16: 4-6

Allan LA, Campbell MK, Milner BJ, Eccles DM, Leonard RCF, Parkin DE, Millers ID, Lessells AM, Kitchener HC, Haites NE (1996) The significance of p53 mutation and over-expression in ovarian cancer prognosis. Int $J$ Gynecol Cancer 6: $483-490$

Anttila MA, Ji H, Juhola MT, Saarikoski SV, Syrjanen KJ (1999) The prognostic significance of $\mathrm{p} 53$ expression quantitated by computerized image analysis in epithelial ovarian cancer. Int J Gynecol Pathol 18: $42-51$

Baekelandt M, Kristensen GB, Nesland JM, Trope CG, Holm R (1999) Clinical significance of apoptosis-related factors p53, Mdm2, and Bcl-2 in advanced ovarian cancer. J Clin Oncol 17: 2061

Bali A, O'Brien PM, Edwards LS, Sutherland RL, Hacker NF, Henshall SM (2004) Cyclin D1, p53, and p21Waf1/Cip1 expression is predictive of poor clinical outcome in serous epithelial ovarian cancer. Clin Cancer Res 10: $5168-5177$

Bartel F, Jung J, Bohnke A, Gradhand E, Zeng K, Thomssen C, Hauptmann $S$ (2008) Both germ line and somatic genetics of the p53 pathway affect ovarian cancer incidence and survival. Clin Cancer Res 14: 89-96

Bartlett JM, Langdon SP, Simpson BJ, Stewart M, Katsaros D, Sismondi P, Love S, Scott WN, Williams AR, Lessells AM, Macleod KG, Smyth JF, Miller WR (1996) The prognostic value of epidermal growth factor receptor mRNA expression in primary ovarian cancer. Br J Cancer 73: $301-306$

Bell DA (2005) Origins and molecular pathology of ovarian cancer. Mod Pathol 18(Suppl 2): S19-S32

Berchuck A, Kamel A, Whitaker R, Kerns B, Olt G, Kinney R, Soper JT, Dodge R, Clarke-Pearson DL, Marks P (1990) Overexpression of HER-2/ neu is associated with poor survival in advanced epithelial ovarian cancer. Cancer Res 50: 4087-4091

Berker B, Dunder I, Ensari A, Cengiz SD (2002) Prognostic value of p53 accumulation in epithelial ovarian carcinomas. Arch Gynecol Obstet 266: 205-209

Bild AH, Potti A, Nevins JR (2006) Linking oncogenic pathways with therapeutic opportunities. Nat Rev Cancer 6: 735-741

Birner P, Schindl M, Obermair A, Breitenecker G, Oberhuber G (2001) Expression of hypoxia-inducible factor 1alpha in epithelial ovarian tumors: its impact on prognosis and on response to chemotherapy. Clin Cancer Res 7: $1661-1668$

Blegen H, Einhorn N, Sjovall K, Roschke A, Ghadimi BM, McShane LM, Nilsson B, Shah K, Ried T, Auer G (2000) Prognostic significance of cell cycle proteins and genomic instability in borderline, early and advanced stage ovarian carcinomas. Int J Gynecol Cancer 10: 477-487

Brustmann H (2007) Poly(adenosine diphosphate-ribose) polymerase expression in serous ovarian carcinoma: correlation with p53, MIB-1, and outcome. Int J Gynecol Pathol 26: $147-153$

Brustmann H (2008) Epidermal growth factor receptor expression in serous ovarian carcinoma: an immunohistochemical study with galectin-3 and cyclin D1 and outcome. Int J Gynecol Pathol 27: 380-389

Camilleri-Broet S, Hardy-Bessard AC, Le Tourneau A, Paraiso D, Levrel O, Leduc B, Bain S, Orfeuvre H, Audouin J, Pujade-Lauraine E (2004) HER-2 overexpression is an independent marker of poor prognosis of advanced primary ovarian carcinoma: a multicenter study of the GINECO group. Ann Oncol 15: 104-112

Cannistra SA (2004) Cancer of the ovary. N Engl J Med 351: 2519-2529

Castellvi J, Garcia A, Rojo F, Ruiz-Marcellan C, Gil A, Baselga J, Ramon YC (2006) Phosphorylated 4E binding protein 1: a hallmark of cell signaling that correlates with survival in ovarian cancer. Cancer 107: 1801-1811

Ceccaroni M, Chieco P, Alboni C, De Laco P, Pagano K, Ceccarelli C, Santini D, Taroni B, Pelusi G (2004) p53 expression, DNA ploidy and mitotic index as prognostic factors in patients with epithelial ovarian carcinoma. Tumori 90: 600-606
Chung CH, Ely K, McGavran L, Varella-Garcia M, Parker J, Parker N, Jarrett C, Carter J, Murphy BA, Netterville J, Burkey BB, Sinard R, Cmelak A, Levy S, Yarbrough WG, Slebos RJ, Hirsch FR (2006) Increased epidermal growth factor receptor gene copy number is associated with poor prognosis in head and neck squamous cell carcinomas. J Clin Oncol 24: $4170-4176$

Concin N, Hofstetter G, Berger A, Gehmacher A, Reimer D, Watrowski R, Tong D, Schuster E, Hefler L, Heim K, Mueller-Holzner E, Marth C, Moll UM, Zeimet AG, Zeillinger R (2005) Clinical relevance of dominantnegative p73 isoforms for responsiveness to chemotherapy and survival in ovarian cancer: Evidence for a crucial p53-p73 cross-talk in vivo. Clin Cancer Res 11: $8372-8383$

Crijns APG, Boezen HM, Schouten JP, Arts HJG, Hofstra RMW, Willemse PHB, Vries de EGE, Van Der Zee AG (2003) Prognostic factors in ovarian cancer: current evidence and future prospects. Eur J Cancer $S$ 1: $127-145$

Darai E, Walker-Combrouze F, Mlika-Cabanne N, Feldmann G, Madelenat P, Scoazec JY (1998) Expression of p53 protein in borderline epithelial ovarian tumors: a clinicopathologic study of 39 cases. Eur J Gynaecol Oncol 19: $144-149$

Darcy KM, Brady WE, McBroom JW, Bell JG, Young RC, McGuire WP, Linnoila RI, Hendricks D, Bonome T, Farley JH, Gynecologic Oncology Group (2008) Associations between p53 overexpression and multiple measures of clinical outcome in high-risk, early stage or suboptimallyresected, advanced stage epithelial ovarian cancers. A Gynecologic Oncology Group study. Gynecol Oncol 111: 487-495

Davidson B, Gotlieb WH, Ben Baruch G, Nesland JM, Bryne M, Goldberg I, Kopolovic J, Berner A (2000) E-Cadherin complex protein expression and survival in ovarian carcinoma. Gynecol Oncol 79: 362-371

de Graeff P, Crijns AP, Ten Hoor KA, Klip HG, Hollema H, Oien K, Bartlett JM, Wisman GB, de Bock GH, De Vries EG, De Jong S, Van Der Zee AG (2008) The ErbB signalling pathway: protein expression and prognostic value in epithelial ovarian cancer. Br J Cancer 99: 341 - 349

de Graeff P, Hall J, Crijns AP, de Bock GH, Paul J, Oien KA, Ten Hoor KA, De Jong S, Hollema H, Bartlett JM, Brown R, Van Der Zee AG (2006) Factors influencing p53 expression in ovarian cancer as a biomarker of clinical outcome in multicentre studies. $\mathrm{Br}$ J Cancer 95: $627-633$

DerSimonian R, Laird N (1986) Meta-analysis in clinical trials. Control Clin Trials 7: $177-188$

Dinh P, Harnett P, Piccart-Gebhart MJ, Awada A (2008) New therapies for ovarian cancer: cytotoxics and molecularly targeted agents. Crit Rev Oncol Hematol 67: 103-112

Egger M, Davey Smith G, Schneider M, Minder C (1997) Bias in metaanalysis detected by a simple, graphical test. BMJ 315: 629-634

Elie C, Geay JF, Morcos M, Le Tourneau A, Girre V, Broet P, Marmey B, Chauvenet L, Audouin J, Pujade-Lauraine E, Camilleri-Broet S (2004) Lack of relationship between EGFR-1 immunohistochemical expression and prognosis in a multicentre clinical trial of 93 patients with advanced primary ovarian epithelial cancer (GINECO group). $\mathrm{Br} J$ Cancer 91: $470-475$

Eltabbakh GH, Belinson JL, Kennedy AW, Biscotti CV, Casey G, Tubbs RR, Blumenson LE (1997) p53 overexpression is not an independent prognostic factor for patients with primary ovarian epithelial cancer. Cancer 80: $892-898$

Fajac A, Benard J, Lhomme C, Rey A, Duvillard P, Rochard F, Bernaudin JF, Riou G (1995) c-erbB2 gene amplification and protein expression in ovarian epithelial tumors: evaluation of their respective prognostic significance by multivariate analysis. Int J Cancer 64: 146-151

Fischer-Colbrie J, Witt A, Heinzl H, Speiser P, Czerwenka K, Sevelda P, Zeillinger R (1997) EGFR and steroid receptors in ovarian carcinoma: comparison with prognostic parameters and outcome of patients. Anticancer Res 17: 613-619 
Galic V, Willner J, Wollan M, Garg R, Garcia R, Goff BA, Gray HJ, Swisher EM (2007) Common polymorphisms in TP53 and MDM2 and the relationship to TP53 mutations and clinical outcomes in women with ovarian and peritoneal carcinomas. Genes Chromosomes Cancer 46: $239-247$

Garcia-Velasco A, Mendiola C, Sanchez-Munoz A, Ballestin C, Colomer R, Cortes-Funes H (2008) Prognostic value of hormonal receptors, p53, ki67 and HER2/neu expression in epithelial ovarian carcinoma. Clin Transl Oncol 10: $367-371$

Giordano G, Azzoni C, D'Adda T, Rocco A, Gnetti L, Froio E, Merisio C, Melpignano M (2008) Human papilloma virus (HPV) status, p16INK4a, and p53 overexpression in epithelial malignant and borderline ovarian neoplasms. Pathol Res Pract 204: 163-174

Goodheart MJ, Ritchie JM, Rose SL, Fruehauf JP, De Young BR, Buller RE (2005) The relationship of molecular markers of p53 function and angiogenesis to prognosis of stage I epithelial ovarian cancer. Clin Cancer Res 11: 3733-3742

Green JA, Berns EMJJ, Coens C, van Luijk I, Thompson-Hehir J, van Diest P, Verheijen RHM, van de Vijver M, van Dam P, Kenter GG, Tjalma W, Ewing PC, Teodorovic I, Vergote I, van der Burg MEL (2006) Alterations in the p53 pathway and prognosis in advanced ovarian cancer: a multifactorial analysis of the EORTC Gynaecological Cancer group (study 55865). Eur J Cancer 42: 2539-2548

Growdon WB, Boisvert SL, Akhavanfard S, Oliva E, Dias-Santagata DC, Kojiro S, Horowitz NS, Iafrate AJ, Borger DR, Rueda BR (2008) Decreased survival in EGFR gene amplified vulvar carcinoma. Gynecol Oncol 111: 289-297

Hall J, Paul J, Brown R (2004) Critical evaluation of p53 as a prognostic marker in ovarian cancer. Expert Rev Mol Med 2004: 1-20

Hartmann LC, Podratz KC, Keeney GL, Kamel NA, Edmonson JH, Grill JP, Su JQ, Katzmann JA, Roche PC (1994) Prognostic significance of p53 immunostaining in epithelial ovarian cancer. J Clin Oncol 12: $64-69$

Havrilesky L, Darcy M, Hamdan H, Priore RL, Leon J, Bell J, Berchuck A (2003) Prognostic significance of p53 mutation and p53 overexpression in advanced epithelial ovarian cancer: a Gynecologic Oncology Group Study. J Clin Oncol 21: 3814-3825

Hawes D, Liu PY, Muggia FM, Wilczynski S, Cote R, Felix J, Terada K, Belt RJ, Alberts DS (2002) Correlation of p53 immunostaining in primary and residual ovarian cancer at the time of positive second-look laparotomy and its prognostic role: a Southwest Oncology Group ancillary study. Gynecol Oncol 87: 17-23

Hayes DF, Bast RC, Desch CE, Fritsche Jr H, Kemeny NE, Jessup JM, Locker GY, Macdonald JS, Mennel RG, Norton L, Ravdin P, Taube S, Winn RJ (1996) Tumor marker utility grading system: a framework to evaluate clinical utility of tumor markers. J Natl Cancer Inst 88: 1456-1466

Higgins JP, Thompson SG (2002) Quantifying heterogeneity in a metaanalysis. Stat Med 21: 1539-1558

Howells RE, Holland T, Dhar KK, Redman CW, Hand P, Hoban PR, Jones PW, Fryer AA, Strange RC (2001) Glutathione S-transferase GSTM1 and GSTT1 genotypes in ovarian cancer: association with p53 expression and survival. Int J Gynecol Cancer 11: 107-112

Iba T, Kigawa J, Kanamori Y, Itamochi H, Oishi T, Simada M, Uegaki K, Naniwa J, Terakawa N (2004) Expression of the c-myc gene as a predictor of chemotherapy response and a prognostic factor in patients with ovarian cancer. Cancer Sci 95: 418-423

Ikeda K, Sakai K, Yamamoto R, Hareyama H, Tsumura N, Watari H, Shimizu M, Minakami H, Sakuragi N (2003) Multivariate analysis for prognostic significance of histologic subtype, GST-pi, MDR-1, and p53 in stages II-IV ovarian cancer. Int J Gynecol Cancer 13: 776-784

Jacquemier J, Moles JP, Penault-Llorca F, Adelaide J, Torrente M, Viens P, Birnbaum D, Theillet C (1994) p53 immunohistochemical analysis in breast cancer with four monoclonal antibodies: comparison of staining and PCR-SSCP results. Br J Cancer 69: 846-852

Jadad AR, Moore RA, Carroll D, Jenkinson C, Reynolds DJ, Gavaghan DJ, McQuay HJ (1996) Assessing the quality of reports of randomized clinical trials: is blinding necessary? Control Clin Trials 17: 1-12

Kaern J, Aghmesheh M, Nesland JM, Danielsen HE, Sandstad B, Friedlander M, Trope C (2005) Prognostic factors in ovarian carcinoma stage III patients. Can biomarkers improve the prediction of short- and long-term survivors? Int J Gynecol Cancer 15: 1014-1022

Kaiser PC, Korner M, Kappeler A, Aebi S (2005) Retinoid receptors in ovarian cancer: expression and prognosis. Ann Oncol 16: 1477-1487

Kassim SK, Ali HS, Sallam MM, Fayed ST, Seada LS, abd-Elkawy E, Seada MA, Khalifa A (1999) Increased bcl-2 expression is associated with primary resistance to chemotherapy in human epithelial ovarian cancer. Clin Biochem 32: $333-338$

Kaufmann M, Von Minckwitz G, Kuhn W, Schmid H, Costa S, Goerttler K, Bastert G (1995) Combination of new biologic parameters as a prognostic index in epithelial ovarian carcinoma. Int J Gynecol Cancer 5: 49-55

Klemi PJ, Pylkkanen L, Kiilholma P, Kurvinen K, Joensuu H (1995) p53 protein detected by immunohistochemistry as a prognostic factor in patients with epithelial ovarian carcinoma. Cancer 76: 1201-1208

Kobel M, Kalloger SE, Boyd N, McKinney S, Mehl E, Palmer C, Leung S, Bowen NJ, Ionescu DN, Rajput A, Prentice LM, Miller D, Santos J, Swenerton K, Gilks CB, Huntsman D (2008) Ovarian carcinoma subtypes are different diseases: implications for biomarker studies. PLoS Med 5: $1749-1760$

Konstantinidou AE, Korkolopoulou P, Vassilopoulos I, Tsenga A, Thymara I, Agapitos E, Patsouris E, Davaris P (2003) Reduced retinoblastoma gene protein to $\mathrm{Ki}-67$ ratio is an adverse prognostic indicator for ovarian adenocarcinoma patients. Gynecol Oncol 88: 369-378

Laframboise S, Chapman W, McLaughlin J, Andrulis IL (2000) p53 mutations in epithelial ovarian cancers: possible role in predicting chemoresistance. Cancer J 6: 302-308

Lassus H, Leminen A, Vayrynen A, Cheng G, Gustafsson JA, Isola J, Butzow $R$ (2004) ERBB2 amplification is superior to protein expression status in predicting patient outcome in serous ovarian carcinoma. Gynecol Oncol 92: $31-39$

Lassus H, Sihto H, Leminen A, Joensuu H, Isola J, Nupponen NN, Butzow R (2006) Gene amplification, mutation, and protein expression of EGFR and mutations of ERBB2 in serous ovarian carcinoma. J Mol Med 84: 671-681

Lee JS, Choi YD, Lee JH, Nam JH, Choi C, Lee MC, Park CS, Juhng SW, Min KW (2006) Expression of cyclooxygenase-2 in epithelial ovarian tumors and its relation to vascular endothelial growth factor and p53 expression. Int J Gynecol Cancer 16(Suppl 1): 247-253

Leffers N, Lambeck AJ, de GP, Bijlsma AY, Daemen T, Van Der Zee AG, Nijman HW (2008) Survival of ovarian cancer patients overexpressing the tumour antigen p53 is diminished in case of MHC class I downregulation. Gynecol Oncol 110: 365-373

Levesque MA, Katsaros D, Massobrio M, Genta F, Yu H, Richiardi G, Fracchioli S, Durando A, Arisio R, Diamandis EP (2000) Evidence for a dose-response effect between p53 (but not p21WAF1/Cip1) protein concentrations, survival, and responsiveness in patients with epithelial ovarian cancer treated with platinum-based chemotherapy. Clin Cancer Res 6: $3260-3270$

Malamou-Mitsi V, Crikoni O, Timotheadou E, Aravantinos G, Vrettou E, Agnantis N, Fountzilas G (2007) Prognostic significance of HER-2, p53 and Bcl-2 in patients with epithelial ovarian cancer. Anticancer Res 27: $1157-1165$

Marx D, Meden H, Ziemek T, Lenthe T, Kuhn W, Schauer A (1998) Expression of the p53 tumour suppressor gene as a prognostic marker in platinum-treated patients with ovarian cancer. Eur J Cancer 34: 845-850

Materna V, Surowiak P, Markwitz E, Spaczynski M, Drag-Zalesinska M, Zabel M, Lage H (2007) Expression of factors involved in regulation of DNA mismatch repair- and apoptosis pathways in ovarian cancer patients. Oncol Rep 17: 505-516

McShane LM, Altman DG, Sauerbrei W, Taube SE, Gion M, Clark GM (2005) REporting recommendations for tumour MARKer prognostic studies (REMARK). Br J Cancer 93: 387-391

Medl M, Sevelda P, Czerwenka K, Dobianer K, Hanak H, Hruza C, Klein M, Leodolter S, Mullauer-Ertl S, Rosen A (1995) DNA amplification of HER-2/neu and INT-2 oncogenes in epithelial ovarian cancer. Gynecol Oncol 59: $321-326$

Moher D, Cook DJ, Eastwood S, Olkin I, Rennie D, Stroup DF (1999) Improving the quality of reports of meta-analyses of randomised controlled trials: the QUOROM statement. Quality of Reporting of Meta-analyses. Lancet 354: 1896-1900

Moher D, Pham B, Jones A, Cook DJ, Jadad AR, Moher M, Tugwell P, Klassen TP (1998) Does quality of reports of randomised trials affect estimates of intervention efficacy reported in meta-analyses? Lancet 352: $609-613$

Nakayama K, Takebayashi Y, Nakayama S, Hata K, Fujiwaki R, Fukumoto M, Miyazaki K (2003) Prognostic value of overexpression of p53 in human ovarian carcinoma patients receiving cisplatin. Cancer Lett 192: $227-235$

Nielsen JS, Jakobsen E, Holund B, Bertelsen K, Jakobsen A (2004) Prognostic significance of p53, Her-2, and EGFR overexpression in borderline and epithelial ovarian cancer. Int J Gynecol Cancer 14: $1086-1096$ 
Oldenhuis CN, Oosting SF, Gietema JA, De Vries EG (2008) Prognostic vs predictive value of biomarkers in oncology. Eur J Cancer 44: 946-953

Ozalp SS, Yalcin OT, Basaran GN, Artan S, Kabukcuoglu S, Minsin TH (2000) Prognostic significance of deletion and overexpression of the p53 gene in epithelial ovarian cancer. Eur J Gynaecol Oncol 21: $282-286$

Parmar MKB, Torri V, Stewart L (1998) Extracting summary statistics to perform meta-analyses of the published literature for survival endpoints. Stat Med 17: 2815-2834

Pham B, Klassen TP, Lawson ML, Moher D (2005) Language of publication restrictions in systematic reviews gave different results depending on whether the intervention was conventional or complementary. J Clin Epidemiol 58: 769-776

Pieretti M, Hopenhayn-Rich C, Khattar NH, Cao Y, Huang B, Tucker TC (2002) Heterogeneity of ovarian cancer: relationships among histological group, stage of disease, tumor markers, patient characteristics, and survival. Cancer Invest 20: 11-23

Pils D, Pinter A, Reibenwein J, Alfanz A, Horak P, Schmid BC, Hefler L, Horvat R, Reinthaller A, Zeillinger R, Krainer M (2007) In ovarian cancer the prognostic influence of HER2/neu is not dependent on the CXCR4/ SDF-1 signalling pathway. Br J Cancer 96: 485 -491

Psyrri A, Kassar M, Yu Z, Bamias A, Weinberger PM, Markakis S, Kowalski D, Camp RL, Rimm DL, Dimopoulos MA (2005) Effect of epidermal growth factor receptor expression level on survival in patients with epithelial ovarian cancer. Clin Cancer Res 11: 8637-8643

Psyrri A, Kountourakis P, Yu Z, Papadimitriou C, Markakis S, Camp RL, Economopoulos T, Dimopoulos MA (2007) Analysis of p53 protein expression levels on ovarian cancer tissue microarray using automated quantitative analysis elucidates prognostic patient subsets. Ann Oncol 18: $709-715$

Raspollini MR, Castiglione F, Garbini F, Villanucci A, Amunni G, Baroni G, Boddi V, Taddei GL (2005) Correlation of epidermal growth factor receptor expression with tumor microdensity vessels and with vascular endothelial growth factor expression in ovarian carcinoma. Int J Surg Pathol 13: $135-142$

Reles A, Wen WH, Schmider A, Gee C, Runnebaum IB, Kilian U, Jones LA, El Naggar A, Minguillon C, Schonborn I, Reich O, Kreienberg R, Lichtenegger W, Press MF (2001) Correlation of p53 mutations with resistance to platinum-based chemotherapy and shortened survival in ovarian cancer. Clin Cancer Res 7: 2984-2997

Saegusa M, Machida BD, Okayasu I (2001) Possible associations among expression of p14(ARF), p16(INK4a), p21(WAF1/CIP1), p27(KIP1), and p53 accumulation and the balance of apoptosis and cell proliferation in ovarian carcinomas. Cancer 92: 1177- 1189

Sagarra RA, Andrade LA, Martinez EZ, Pinto GA, Syrjanen KJ, Derchain SF (2002) P53 and Bcl-2 as prognostic predictors in epithelial ovarian cancer. Int J Gynecol Cancer 12: 720-727

Scambia G, Benedetti-Panici P, Ferrandina G, Distefano M, Salerno G, Romanini ME, Fagotti A, Mancuso S (1995) Epidermal growth factor, oestrogen and progesterone receptor expression in primary ovarian cancer: correlation with clinical outcome and response to chemotherapy. Br I Cancer 72: 361 - 366

Schilder RJ, Sill MW, Chen X, Darcy KM, Decesare SL, Lewandowski G, Lee RB, Arciero CA, Wu H, Godwin AK (2005) Phase II study of gefitinib in patients with relapsed or persistent ovarian or primary peritoneal carcinoma and evaluation of epidermal growth factor receptor mutations and immunohistochemical expression: a Gynecologic Oncology Group Study. Clin Cancer Res 11: 5539-5548

Schildkraut JM, Halabi S, Bastos E, Marchbanks PA, McDonald JA, Berchuck A (2000) Prognostic factors in early-onset epithelial ovarian cancer: a population-based study. Obstet Gynecol 95: 119-127

Schuyer M, van der Burg ME, Henzen-Logmans SC, Fieret JH, Klijn JG, Look MP, Foekens JA, Stoter G, Berns EM (2001) Reduced expression of $\mathrm{BAX}$ is associated with poor prognosis in patients with epithelial ovarian cancer: a multifactorial analysis of TP53, p21, BAX and BCL-2. $B r J$ Cancer 85: 1359 - 1367

Seo SS, Song YS, Kang DH, Park IA, Bang YJ, Kang SB, Lee HP (2004) Expression of cyclooxygenase-2 in association with clinicopathological prognostic factors and molecular markers in epithelial ovarian cancer. Gynecol Oncol 92: 927-935

Shahin MS, Hughes JH, Sood AK, Buller RE (2000) The prognostic significance of p53 tumor suppressor gene alterations in ovarian carcinoma. Cancer 89: 2006-2017

Silvestrini R, Daidone MG, Veneroni S, Benini E, Scarfone G, Zanaboni F, Villa A, Presti M, Danese S, Bolis G (1998) The clinical predictivity of biomarkers of stage III-IV epithelial ovarian cancer in a prospective randomized treatment protocol. Cancer 82: 159-167

Simon R, Altman DG (1994) Statistical aspects of prognostic factor studies in oncology. Br J Cancer 69: 979-985

Skirnisdottir I, Sorbe B, Seidal T (2001a) P53, bcl-2, and bax: their relationship and effect on prognosis in early stage epithelial ovarian carcinoma. Int J Gynecol Cancer 11: 147-158

Skirnisdottir I, Sorbe B, Seidal T (2001b) The growth factor receptors HER2/neu and EGFR, their relationship, and their effects on the prognosis in early stage (FIGO I-II) epithelial ovarian carcinoma. Int J Gynecol Cancer 11: $119-129$

Steffensen KD, Waldstrom M, Jeppesen U, Jakobsen E, Brandslund I, Jakobsen A (2007) The prognostic importance of cyclooxygenase 2 and HER2 expression in epithelial ovarian cancer. Int J Gynecol Cancer 17: $798-807$

Surowiak P, Materna V, Kaplenko I, Spaczynski M, Dietel M, Lage H, Zabel M (2006) Topoisomerase 1A, HER/2neu and Ki67 expression in paired primary and relapse ovarian cancer tissue samples. Histol Histopathol 21: $713-720$

Tachibana M, Watanabe J, Matsushima Y, Nishida K, Kobayashi Y, Fujimura M, Shiromizu K (2003) Independence of the prognostic value of tumor suppressor protein expression in ovarian adenocarcinomas: A multivariate analysis of expression of $\mathrm{p} 53$, retinoblastoma, and related proteins. Int J Gynecol Cancer 13: 598-606

Terauchi F, Okamoto A, Nagashima T, Kobayashi Y, Moritake T, Yamamoto Y, Takakura S, Iwaki S, Ogura H (2005) Clinical significance of $\mathrm{p} 21$ (WAF1/CIP1) and $\mathrm{p} 53$ expression in serous cystadenocarcinoma of the ovary. Oncol Rep 14: $363-368$

Thompson SG, Higgins JP (2002) How should meta-regression analyses be undertaken and interpreted? Stat Med 21: 1559-1573

Tomsova M, Melichar B, Sedlakova I, Steiner I (2008) Prognostic significance of $\mathrm{CD} 3+$ tumor-infiltrating lymphocytes in ovarian carcinoma. Gynecol Oncol 108: 415-420

Tuefferd M, Couturier J, Penault-Llorca F, Vincent-Salomon A, Broet P, Guastalla JP, Allouache D, Combe M, Weber B, PujadeLauraine E, Camilleri-Broet S (2007) HER2 status in ovarian carcinomas: a multicenter GINECO study of 320 patients. PLOS ONE 2: e1138

Ueno Y, Enomoto T, Otsuki Y, Sugita N, Nakashima R, Yoshino K, Kuragaki C, Ueda Y, Aki T, Ikegami H, Yamazaki M, Ito K, Nagamatsu M, Nishizaki T, Asada M, Kameda T, Wakimoto A, Mizutani T, Yamada T, Murata Y (2006) Prognostic significance of p53 mutation in suboptimally resected advanced ovarian carcinoma treated with the combination chemotherapy of paclitaxel and carboplatin. Cancer Let 241: $289-300$

Vartiainen J, Lassus H, Lehtovirta P, Finne P, Alfthan H, Butzow R, Stenman UH (2008) Combination of serum hCG beta and p53 tissue expression defines distinct subgroups of serous ovarian carcinoma. Int $J$ Cancer 122: 2125-2129

Vergote I, De Brabanter J, Fyles A, Bertelsen K, Einhorn N, Sevelda P, Gore ME, Kaern J, Verrelst H, Sjovall K, Timmerman D, Vandewalle J, Van Gramberen M, Trope CG (2001) Prognostic importance of degree of differentiation and cyst rupture in stage I invasive epithelial ovarian carcinoma. Lancet 357: 176-182

Verri E, Guglielmini P, Puntoni M, Perdelli L, Papadia A, Lorenzi P, Rubagotti A, Ragni N, Boccardo F (2005) HER2/neu oncoprotein overexpression in epithelial ovarian cancer: evaluation of its prevalence and prognostic significance. Clinical study. Oncology 68: $154-161$

Viale G, Maisonneuve P, Bonoldi E, Di Bacco A, Bevilacqua P, Panizzoni GA, Radaelli U, Gasparini G (1997) The combined evaluation of p53 accumulation and of Ki-67 (MIB1) labelling index provides independent information on overall survival of ovarian carcinoma patients. Ann Oncol 8: $469-476$

Wang Y, Kristensen GB, Helland A, Nesland JM, Borresen-Dale AL, Holm R (2005) Protein expression and prognostic value of genes in the erb-b signaling pathway in advanced ovarian carcinomas. Am J Clin Patho 124: $392-401$

Wang ZR, Liu W, Smith ST, Parrish RS, Young SR (1999) c-myc and chromosome 8 centromere studies of ovarian cancer by interphase FISH. Exp Mol Pathol 66: $140-148$

Wen WH, Reles A, Runnebaum IB, Sullivan-Halley J, Bernstein L, Jones LA, Felix JC, Kreienberg R, El Naggar A, Press MF (1999) p53 mutations and expression in ovarian cancers: correlation with overall survival. Int Gynecol Pathol 18: 29-41 
p53, EGFR and HER-2/neu in ovarian cancer

$P$ de Graeff et al

Whiting P, Rutjes AW, Reitsma JB, Bossuyt PM, Kleijnen J (2003) The development of QUADAS: a tool for the quality assessment of studies of diagnostic accuracy included in systematic reviews. BMC Med Res Methodol 3: 25

Winter III WE, Maxwell GL, Tian C, Carlson JW, Ozols RF, Rose PG, Markman M, Armstrong DK, Muggia F, McGuire WP (2007) Prognostic factors for III stage epithelial ovarian cancer: a Gynecologic Oncology Group Study. J Clin Oncol 25: 3621-3627
Wisman GB, Hollema H, Helder MN, Knol AJ, Van der Meer GT, Krans M, De Jong S, De Vries EG, Van Der Zee AG (2003) Telomerase in relation to expression of p53, c-Myc and estrogen receptor in ovarian tumours. Int $J$ Oncol 23: $1451-1459$

Yakirevich E, Sabo E, Naroditsky I, Sova Y, Lavie O, Resnick MB (2006) Multidrug resistance-related phenotype and apoptosis-related protein expression in ovarian serous carcinomas. Gynecol Oncol 100: $152-159$ 